\title{
OPEN Modulation of solute diffusivity in brain tissue as a novel mechanism of transcranial direct current stimulation (tDCS)
}

\begin{abstract}
Yifan Xia, Wasem Khalid, Zhaokai Yin, Guangyao Huang, Marom Bikson \& Bingmei M. Fu ${ }^{凶}$
The breadth of brain disorders and functions reported responsive to transcranial direct current stimulation (tDCS) suggests a generalizable mechanism of action. Prior efforts characterized its cellular targets including neuron, glia and endothelial cells. We propose tDCS also modulates the substance transport in brain tissue. High resolution multiphoton microscopy imaged the spread across rat brain tissue of fluorescently-labeled solutes injected through the carotid artery after tDCS. The effective solute diffusion coefficient of brain tissue $\left(D_{\text {eff }}\right)$ was determined from the spatio-temporal solute concentration profiles using an unsteady diffusion transport model. 5-10 min post 20 min-1 mA tDCS, $D_{\text {eff }}$ increased by $~ 10 \%$ for a small solute, sodium fluorescein, and $~ 120 \%$ for larger solutes, BSA and Dex-70k. All increases in $D_{\text {eff }}$ returned to the control level 25-30 min post tDCS. A mathematical model for $D_{\text {eff }}$ in the extracelluar space (ECS) further predicts that this dose of tDCS increases $D_{\text {eff }}$ by transiently enhancing the brain ECS gap spacing by 1.5 -fold and accordingly reducing the extracellular matrix density. The cascades leading ECS modulation and its impact on excitability, synaptic function, plasticity, and brain clearance require further study. Modulation of solute diffusivity and ECS could explain diverse outcomes of tDCS and suggest novel therapeutic strategies.
\end{abstract}

Transcranial direct current stimulation (tDCS) generates static electric fields in the brain leading to lasting changes in brain function ${ }^{1-4}$. The breadth of applications $\mathrm{tDCS}$ is investigated for ${ }^{5-8}$ suggests a mechanism of action that is on the one hand generalizable ${ }^{9-11}$ while on the other hand tunable to specific outcomes ${ }^{12-14}$. As with other forms of neuromodulation ${ }^{15,16}$, research on $\mathrm{tDCS}$ cellular mechanisms has focused on characterizing which neuronal elements are activated ${ }^{9,17-19}$, which has been extended to consider additional cells types notably glial $^{20,21}$ and endothelial cells ${ }^{22,23}$.

The wall of cerebral microvessels is named the blood-brain barrier (BBB) which tightly regulates the brain micro-environment including metabolic capacity and clearance. Being a protecting barrier, the BBB consists of endothelial cells (ECs) with tight junctions between adjacent ECs, which are wrapped by the basement membrane (BM), pericytes and astrocyte foot processes ${ }^{24-26}$. tDCS modulates brain vascular function ${ }^{9,27-30}$ and nitric oxide (NO) signaling ${ }^{31}$ including in patients with Alzheimer's disease ${ }^{32}$. Cancel et al. ${ }^{22}$ showed that direct current stimulation can modulate hydraulic conductivity of an in vitro BBB model through tight-junction electro-osmosis. Shin et al. ${ }^{23}$ demonstrated that tDCS transiently increases the BBB permeability $(\mathrm{P})$ in rat brain ${ }^{22,23}$ through activation of nitric oxide synthase (NOS).

Brain parenchyma is essentially composed of two regions: cellular elements (neurons and glial cells), and the gaps between these elements, which is known as the extracellular space (ECS) ${ }^{33-35}$. Typically occupying $\sim 20 \%$ of the total brain tissue volume ${ }^{34,36,37}$, the brain ECS contains interstitial fluid with ions and negatively charged extracellular matrix $(\mathrm{ECM})^{38,39}$. The ECS is a dynamic regulator for the transport of extracellular molecules ${ }^{37,40,41}$, playing a crucial roles in neural growth, excitability, signaling, and plasticity ${ }^{42,43}$. The objective of the current study is to test if tDCS modulates the ECS, as measurable by substance transport in brain tissue, and as distinguishable from additional effects increasing the BBB permeability.

We used a small solute, sodium fluorescein (MW 376), and two large solutes, BSA (bovine serum album, MW 69k) with negative charge (charge number - 19) and Dex-70k with no charge as the representative test substances and quantified their effective diffusion coefficients $\mathrm{D}_{\text {eff }}$ in rat brain tissue under control and in response to tDCS treatments. $\mathrm{D}_{\text {eff }}$ is a quantitative indicator for substance transport in porous media, such as brain tissue. 


\begin{tabular}{|l|l|l|l|l|l|l|}
\hline Solute & $\mathbf{n}$ & Vessel radius $(\boldsymbol{\mu m})$ & $\begin{array}{l}\mathbf{P}(\mathbf{m e a s u r e d}) \\
\left(\times \mathbf{1 0}^{-7} \mathbf{~ c m} / \mathbf{s}\right)\end{array}$ & $\begin{array}{l}\mathbf{P}(\text { corrected for RBCs) } \\
\left(\times \mathbf{1 0}^{-7} \mathbf{c m} / \mathbf{s}\right)\end{array}$ & $\begin{array}{l}\mathbf{P}(\text { corrected for RBCs and free dye }) \\
\left(\times \mathbf{1 0}^{-7} \mathbf{~ c m} / \mathbf{s}\right)\end{array}$ & $\begin{array}{l}\mathbf{P}(\text { corrected for RBCs, free dye, and } \\
\text { solvent drag) } \\
\left(\times \mathbf{1 0}^{-7} \mathbf{c m} / \mathbf{s}\right)\end{array}$ \\
\hline Sodium fluorescein & 8 & $10.2 \pm 0.1$ & $17.51 \pm 2.34$ & $15.77 \pm 2.11$ & $15.77 \pm 2.11$ & $\begin{array}{l}15.77 \pm 2.11 \\
\left(\mathrm{~L}_{\mathrm{p}, \text { control }}=2 \times 10^{-9}\right)\end{array}$ \\
\hline $\begin{array}{l}\text { FITC-BSA } \\
(-19)\end{array}$ & 10 & $12.3 \pm 0.5$ & $1.13 \pm 0.12$ & $1.02 \pm 0.11$ & $0.99 \pm 0.11$ & $\begin{array}{l}0.99 \pm 0.11 \\
\left(\mathrm{~L}_{\mathrm{p}, \text { control }}=2 \times 10^{-9}\right)\end{array}$ \\
\hline FITC-Dex-70k & 11 & $11.5 \pm 0.1$ & $1.38 \pm 0.06$ & $1.24 \pm 0.05$ & $1.22 \pm 0.05$ & $\begin{array}{l}1.22 \pm 0.05 \\
\left(\mathrm{~L}_{\mathrm{p}, \text { control }}=2 \times 10^{-9}\right)\end{array}$ \\
\hline
\end{tabular}

Table 1. Measured and corrected control permeability. Values are mean \pm SE. $n=$ number of vessels. Hydraulic conductivity $\mathrm{L}_{\mathrm{p}}$ in $\mathrm{cm} / \mathrm{s} / \mathrm{cm} \mathrm{H}_{2} \mathrm{O}$. Control $\mathrm{L}_{\mathrm{p}, \text { control }}$ is from Kimura et al. (1993).

\begin{tabular}{|l|c|l|}
\hline Solute & $\frac{\mathbf{P} 5-\mathbf{1 0} \text { min post tDCS }}{\mathbf{P}_{\text {control }}}$ & $\frac{\mathbf{P} \mathbf{2 5}-\mathbf{3 0} \text { min post tDCS }}{\mathbf{P}_{\text {control }}}$ \\
\hline Sodium fluorescein & $13.2 \pm 2.1(\mathrm{n}=5)$ & $1.0 \pm 0.2(\mathrm{n}=6)$ \\
\hline $\begin{array}{l}\text { FITC-BSA } \\
(-19)\end{array}$ & $104.6 \pm 19.7(\mathrm{n}=7)$ & $1.2 \pm 0.3(\mathrm{n}=8)$ \\
\hline FITC-Dex-70k & $86.7 \pm 9.8(\mathrm{n}=7)$ & $1.3 \pm 0.4(\mathrm{n}=7)$ \\
\hline
\end{tabular}

Table 2. $\mathrm{tDCS}$ modulated permeability. Values are mean \pm SE. $n=$ number of vessels.

To do this, we employed our newly developed non-invasive multiphoton microscopy ${ }^{44}$ to both confirm changes in BBB permeability $\mathrm{P}^{23}$ and test $\mathrm{D}_{\text {eff }}$ under control and after $\mathrm{tDCS}$ treatment. The solution with the fluorescently labeled solutes was injected into the rat cerebral circulation via the ipsilateral carotid artery. Simultaneously, the 3-D images of a post-capillary venule and its surrounding area in the rat brain tissue 100-200 $\mu \mathrm{m}$ below the pia mater were collected by laser scanning multiphoton microscopy. The $\mathrm{P}$ and $\mathrm{D}_{\text {eff }}$ were determined from the collected dye spreading images. Specifically, $\mathrm{D}_{\text {eff }}$ was estimated from the spatio-temporal solute concentration (fluorescence intensity) profiles using an unsteady diffusion transport model.

We report tDCS transiently enhance the effective solute diffusion coefficient $\mathrm{D}_{\text {eff }}$ in rat brain tissue Based on our measurements for $\mathrm{D}_{\text {eff }}$ of various sized solutes and the predicted width of the brain $\mathrm{ECS}^{45}$, a model for the restricted diffusion of a solute in a slit filled with fiber matrix predicted that tDCS increases $\mathrm{D}_{\text {eff }}$ by transiently enhancing the width of the brain ECS and reducing ECM density accordingly. Our results thus revealed a new motion of action of tDCS, in parallel to direct neuronal or glial stimulation and enhancement of the BBB permeability. By modulating the ECS, DCS may achieve its therapeutic effect by increasing metabolic capacity and brain clearance mechanisms. Our findings also suggest that $\mathrm{tDCS}$ can be used as a non-invasive, tolerated, and low-cost approach for the enhancement of the brain drug delivery, especially macromolecules, delivered through the $\mathrm{BBB}^{23}$ or $\mathrm{CSF}^{46}$.

\section{Results}

A customized high-resolution multiphoton microscopy system was used to image the spread across rat brain tissue of fluorescently-labeled solutes following their injection through the carotid artery in response to tDCS or under control (not stimulation) conditions (see "Methods" section). We assessed both BBB permeability (P) and the effective solute diffusion coefficient of brain tissue $\left(\mathrm{D}_{\text {eff }}\right)$ at two time points $(\sim 5 \mathrm{~min}$ and $\sim 25 \mathrm{~min})$ after tDCS.

Effects of tDCS on the BBB solute permeability (P). Table 1 summarizes the measured BBB permeability $\mathrm{P}$ to various sized solutes under control and the corrections due to the influence from the residue red blood cells (RBCs) in the fluorescent solution perfused microvessel, free dye in the solution of the FITC-conjugated solutes and the solvent drag from the water permeability (hydraulic conductivity) of the microvessel. It shows that $\mathrm{P}$ to the small molecule, sodium fluorescein $(\mathrm{NaFl}, \mathrm{MW}=376)$, is about 13 and 15 folds of that to the large molecules, Dex-70k and BSA (MW 69k), which have similar size but one is neutral and another carries negative charge. The net charge number of FITC-BSA is $-19^{47}$. Since both the endothelial surface glycocalyx and the extracellular matrix in the basement membrane of the BBB carry negative charge ${ }^{48}, \mathrm{P}$ to negatively charged BSA $\left(0.99 \pm 0.11 \times 10^{-7} \mathrm{~cm} / \mathrm{s}\right)$ is less than that to neutral Dex-70k $\left(1.22 \pm 0.05 \times 10^{-7} \mathrm{~cm} / \mathrm{s}, p=0.03\right)$. Those values for the control P of the BBB were used in Eq. (6) to predict the spatio-temporal solute concentration profiles in the brain tissue. Matching the predicted with the measured profiles allowed us to determine the effective solute brain tissue diffusion coefficient $\mathrm{D}_{\text {eff }}$ under control conditions.

Table 2 demonstrates the effects of tDCS on P to various sized solutes. Due to the limitation of our current technique, we can only determine the P post tDCS treatment. We found that 5-10 min post $20 \mathrm{~min}-1 \mathrm{~mA}$ tDCS significantly increased $\mathrm{P}$ to $\mathrm{NaFl}, \mathrm{BSA}$ and Dex-70k to 13.2 -fold, 104.6-fold, and 86.7-fold $(p<0.01)$, respectively. All the increased $\mathrm{P}$ by tDCS returned to their control values in $25-30 \mathrm{~min}(p>0.1)$. These values of $\mathrm{P}$ post tDCS treatment were inserted in Eq. (6) to find the corresponding $D_{\text {eff }} 5-10 \mathrm{~min}$ and $25-30 \mathrm{~min}$ post $\mathrm{tDCS}$ treatment. 
Control
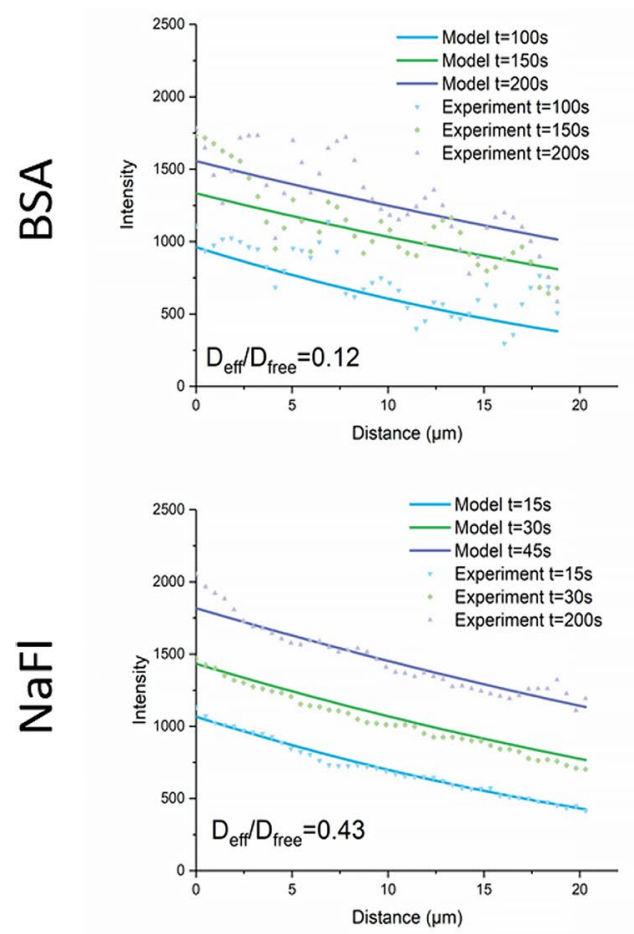

5-10 mins post tDCS
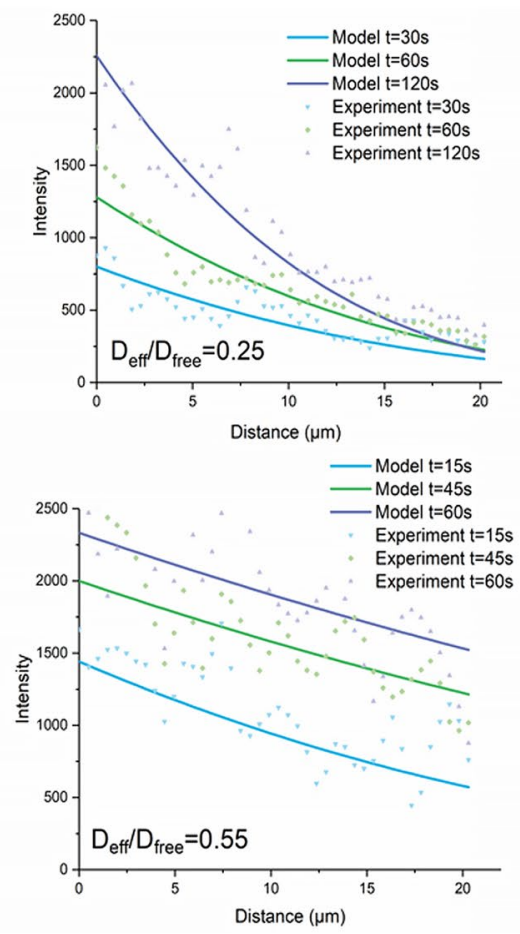

25-30 mins post tDCS
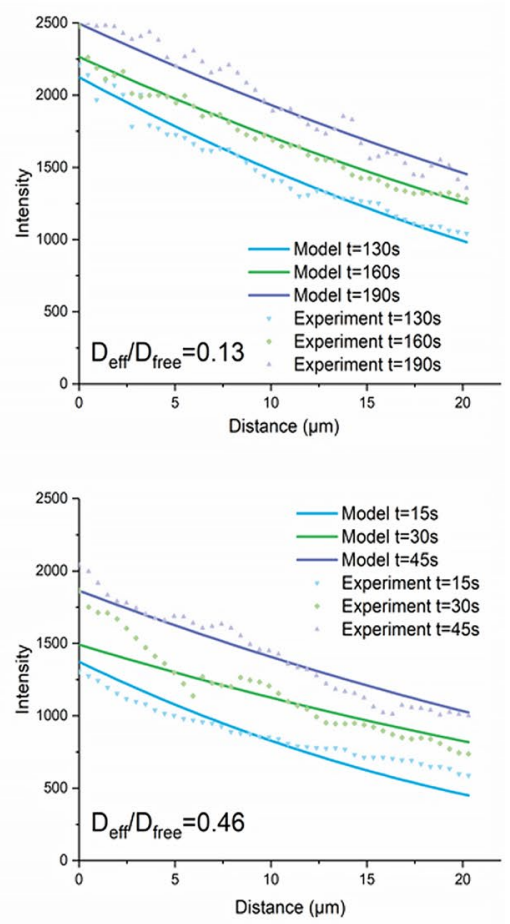

Figure 1. Effects of $\mathrm{tDCS}$ on solute transport in the brain tissue $\left(\mathrm{D}_{\text {eff }}\right)$. The dots are the measured spatialtemporal intensity profiles of the spreading fluorescently labeled solutes in the brain tissue and the smooth lines are the model predictions with the best fitting values of $\mathrm{D}_{\text {eff }} / \mathrm{D}_{\text {free }}$, the ratio of the solute effective diffusion coefficient to its free diffusion coefficient. The top panel is for a large solute, FITC-BSA and the bottom panel for a small solute, sodium fluorescein $(\mathrm{NaFl})$, under control, 5-10 min, and 25-30 min post tDCS, respectively.

\begin{tabular}{|c|c|c|c|c|c|}
\hline Solute & Stokes radius (nm) & $\begin{array}{l}D_{\text {free }} \\
\left(\times 10^{-7} \mathrm{~cm}^{2} / \mathrm{s}\right)\end{array}$ & $\frac{D_{\text {effcontrol }}}{D_{\text {free }}}$ & $\frac{\mathrm{D}_{\text {eff } 5-10 \min \text { posttDCS }}}{\mathrm{D}_{\text {free }}}$ & $\frac{\mathrm{D}_{\text {eff } 25-30 \mathrm{~min} \text { posttDCS }}}{\mathrm{D}_{\text {free }}}$ \\
\hline Sodium fluorescein & 0.45 & 56.2 & $\begin{array}{l}0.45 \pm 0.03 \\
(\mathrm{n}=5)\end{array}$ & $\begin{array}{l}0.50 \pm 0.03 \\
(\mathrm{n}=5)\end{array}$ & $\begin{array}{l}0.45 \pm 0.01 \\
(\mathrm{n}=6)\end{array}$ \\
\hline $\begin{array}{l}\text { FITC-BSA } \\
(-19)\end{array}$ & 3.5 & 8.83 & $\begin{array}{l}0.11 \pm 0.02 \\
(n=7)\end{array}$ & $\begin{array}{l}0.24 \pm 0.05 \\
(\mathrm{n}=7)\end{array}$ & $\begin{array}{l}0.12 \pm 0.02 \\
(\mathrm{n}=8)\end{array}$ \\
\hline FITC-Dex-70k & 3.6 & 7.23 & $\begin{array}{l}0.11 \pm 0.03 \\
(\mathrm{n}=6)\end{array}$ & $\begin{array}{l}0.25 \pm 0.04 \\
(\mathrm{n}=7)\end{array}$ & $\begin{array}{l}0.12 \pm 0.01 \\
(\mathrm{n}=7)\end{array}$ \\
\hline
\end{tabular}

Table 3. tDCS modulated effective solute diffusion coefficients in brain tissue. Values are mean \pm SD. $\mathrm{n}=$ number of vessels.

Effects of tDCS on solute transport in brain tissue $\left(D_{\text {eff }}\right)$. Figure 1 demonstrates the effects of tDCS on solute transport in brain tissue, which is quantified by the effective solute diffusion coefficient in brain tissue $\mathrm{D}_{\text {eff }}$. The upper panel shows the effect of $\mathrm{tDCS}$ on $\mathrm{D}_{\text {eff }}$ of the large solute, BSA, and the bottom panel shows that on $\mathrm{D}_{\text {eff }}$ of the small solute, sodium fluorescein. The effect of tDCS on $\mathrm{D}_{\text {eff }}$ of neutral Dex-70k is similar to that of negatively charged BSA with the same size. In each plot shown in Fig. 1, the colored dots are the measured spatiotemporal solute concentration profiles in the brain tissue surrounding an individual microvessel (see Fig. 4C,D), while the colored lines are the best matching profiles predicted by an unsteady diffusion solute transport model (Eqs. 5-8) when the $\mathrm{D}_{\text {eff }}$ is properly chosen. Under control, $\mathrm{D}_{\text {eff }} / \mathrm{D}_{\text {free }}$ is 0.12 for $\mathrm{BSA}$ in the surrounding brain tissue of one microvessel shown in the upper left plot. $\mathrm{D}_{\text {free }}$ is the solute diffusion coefficient in aqueous solution (e.g. interstitial fluid) at $37^{\circ} \mathrm{C}$ (see Table 3). 5-10 min post tDCS treatment, $D_{\text {eff }} / D_{\text {free }}$ becomes 0.25 for BSA in the surrounding tissue of another microvessel shown in the upper middle plot. After 25-30 min post tDCS treatment, $\mathrm{D}_{\text {eff }} / \mathrm{D}_{\text {free }}$ returns to 0.13 for BSA in the surrounding tissue of a different microvessel shown in the upper right plot. The bottom panel shows the effect of $\mathrm{tDCS}$ on $\mathrm{D}_{\text {eff }}$ of sodium fluorescein $(\mathrm{NaFl})$. Since NaFl (Stokes radius $\sim 0.45 \mathrm{~nm}$ ) is much smaller than BSA (Stokes radius $\sim 3.5 \mathrm{~nm}$ ) and Dex-70k (Stokes radius $\sim 3.6 \mathrm{~nm}$ ), not only is its $\mathrm{D}_{\text {free }}$ much larger, about one order of magnitude higher of those of BSA and Dex-70k, but also the relative transport in the brain tissue $\mathrm{D}_{\text {eff }} / \mathrm{D}_{\text {free, }}$, which is 0.43 under control (lower left plot in Fig. 1), 0.55, 5-10 min post tDCS (lower middle plot) and $0.46,25-30$ min post tDCS (lower right plot). Table 3 summarizes the values for $\mathrm{D}_{\text {free }}$ of sodium fluorescein, BSA (negatively charged, charge number - 19) and Dex-70k (neutral), and $\mathrm{D}_{\text {eff }} l$ 


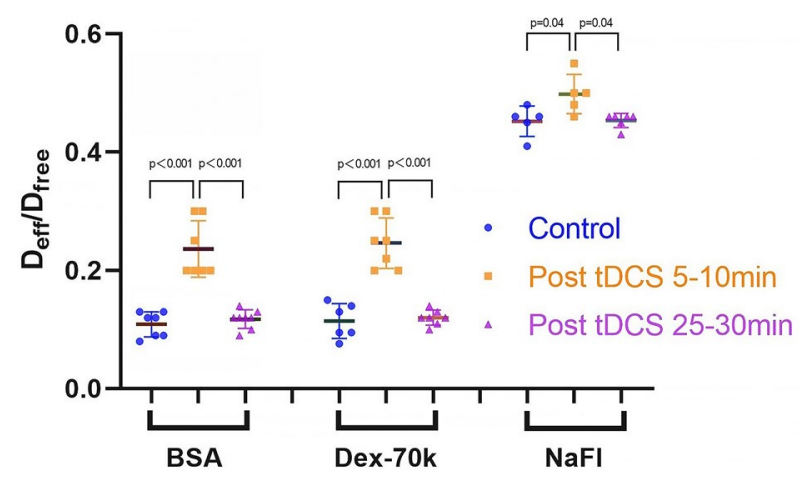

Figure 2. Comparison of the effects of $\mathrm{tDCS}$ on solute transport in the brain tissue for various sized solutes. $\mathrm{D}_{\text {eff }} / \mathrm{D}_{\text {free }}$ for the large solutes, negatively charged FITC-BSA and neutral FITC-Dex-70k and for a small solute, sodium fluorescein (NaFl), under control, 5-10 min and 25-30 min post tDCS.

$D_{\text {free }}$ for each solute under control, 5-10 min and 25-30 min post tDCS, respectively. Figure 2 shows the comparison of $\mathrm{D}_{\text {eff }} / \mathrm{D}_{\text {free }}$ for each solute under these conditions. We can see that $\mathrm{D}_{\text {eff }} / \mathrm{D}_{\text {free }}$ increases from 0.11 under control to 0.24 (or 0.25), 5-10 min post tDCS for the large solutes, BSA and Dex-70k, 2.2-fold. However, for the small solute, sodium fluorescein, $\mathrm{D}_{\text {eff }} / \mathrm{D}_{\text {free }}$ increases from 0.45 to 0.50 , only $\sim 1.1$-fold.

\section{Discussion}

Expanding on prior mechanisms of action of tDCS such as neuronal polarization ${ }^{49-52}$, enhancement in regional blood flow ${ }^{9,27-30,53,54}$ and in blood nitric oxide (NO) levels ${ }^{31,32}$, as well as transient increase in the BBB permeability ${ }^{23}$, our current study uncovered a new target of tDCS: the extracellular space (ECS). By employing non-invasive high resolution (submicron) multiphoton microscopy ${ }^{44}$ to image solute spreading around cerebral microvessels in rat brain and fitting the spatio-temporal solute distribution profiles by an unsteady diffusion transport model, we report that tDCS transiently increases the effective solute diffusion coefficients in rat brain tissue $\mathrm{D}_{\text {eff }}$ to various sized solutes. The increasing level is dependent on the size of the solute but independent of the charge carried by the solute for the size of the solutes under this study.

The brain includes functional cellular elements (neurons and glial cells), transport systems including the blood vasculature and $\mathrm{BBB}$, and the ECS surrounding the cellular elements and blood vasculature. Under typical conditions, about $20 \%$ of the total brain tissue is occupied by the ECS ${ }^{34,36,55}$. Aging as well as CNS diseases and injuries can significantly change the percentage of ECS volume in brain tissue ${ }^{56,57}$. ECS volume fraction can decrease by $\sim 25 \%$ with late aging ${ }^{34}$, and in rodent models, learning deficits are correlated with decrease in ECS fraction and altered diffusion parameters ${ }^{58}$. In a mouse model of Alzheimer's disease, a further $\sim 50 \%$ reduction in volume fraction and $\sim 5 \%$ diffusivity decrease were closely related to plaque deposition, and associated impaired navigation ${ }^{57}$. ECS decreases several fold (to $~ 5 \%$ ) minutes after severe ischemia ${ }^{59}$. Altered ECS fraction and diffusivity is reported in animal models of Parkinson's disease, epilepsy, multiple sclerosis ${ }^{34,60,61}$. Changes in ECS diffusion would broadly be expected in any cases of inflammation edema, or progressive neurodegeneration ${ }^{34}$. Despite the role of the ECS in brain function and disease, interventions to target ECS are either non-specific (e.g. osmotic stress) or not clinically translatable (e.g. genetic modification). In contrast, tDCS is safe ${ }^{2,62,63}$ and broadly used even on healthy subjects ${ }^{64,65}$.

The gaps between cells forming the ECS are $~ 38-64 \mathrm{~nm}^{37,45}$. The ECS is filled with negatively charged extracellular matrix (ECM) and interstitial fluid that is similar with ionic composition to the cerebrospinal fluid (CSF) that maintains an ionic microenvironment important in nerve and glial cell function as well as the vascular osmotic pressure ${ }^{66,67}$. Brain ECM consists of a matrix-like network formed around a backbone of hyaluronic acid (HA), a long, highly hydrated non-sulfated glycosaminoglycan, chondroitin sulfate (CS) and heparan sulfate (HS) proteoglycans along with various glycoproteins, laminins and collagens ${ }^{36,38-40}$. Both the cell membranes enclosing the ECS and the ECM inside the ECS contribute significant resistance to the solute transport in the ECS (brain tissue) especially to large solutes. To predict this resistance and to estimate the effective solute diffusion coefficients in the brain ECS, we used the following simplified formula, derived from rigorous theoretical models from hydrodynamics and transport phenomena and summarized in ${ }^{68}$. The diffusion transport of a solute is retarded by the friction between the solute and the cell membranes/ECM and by the steric hindrance due to the existence of the cell membranes and the ECM. The effective solute diffusion coefficient thus changes with the gap spacing of the ECS, ECM density/arrangements and the solute size. In a fiber matrix (ECM) without boundaries,

$$
\frac{D_{\text {matrix }}}{D_{\text {free }}}=1-\left[(1-\varepsilon)^{0.5}\left(1+\frac{2 a}{\pi^{0.5} r_{f}}\right)\right]
$$

Here, $a$ is the solute radius, $r_{f}$ is the fiber radius, $S_{f}$ is the volume fraction of fibers in ECM, $\varepsilon=1-S_{f}$ is the void volume fraction. $D_{\text {free }}$ is the solute diffusion coefficient in free aqueous solution (CSF) at $37^{\circ} \mathrm{C}$ in our study ${ }^{69}$. In the ECS filled with ECM, 


\begin{tabular}{|c|c|c|c|}
\hline Solute & Stokes radius (nm) & $\begin{array}{l}\left.\frac{D_{\text {effcontrol }}}{\left(\mathrm{D}_{\text {free }}\right.}=40 \mathrm{~nm}, \mathrm{~S}_{\mathrm{f}}=0.17\right)\end{array}$ & $\begin{array}{l}\frac{D_{\text {eff } 5-10 \text { min posttics }}}{\left(\mathrm{W}=\text { D }_{\text {free }} \mathbf{~ n m}, S_{\mathrm{f}}=\mathbf{0 . 1 1}\right)}\end{array}$ \\
\hline Sodium fluorescein & 0.45 & 0.441 & 0.512 \\
\hline $\begin{array}{l}\text { FITC-BSA } \\
(-19)\end{array}$ & 3.5 & 0.124 & 0.254 \\
\hline FITC-Dex-70k & 3.6 & 0.117 & 0.247 \\
\hline
\end{tabular}

Table 4. Model predictions for effective solute diffusion coefficients in brain tissue. W, gap spacing in brain extracellular space (ECS); $\mathrm{S}_{\mathrm{f}}$, volume fraction of fibers in ECM.

$$
\frac{D_{E C S}}{D_{\text {free }}}=\left\{1-\left[(1-\varepsilon)^{0.5}\left(1+\frac{2 a}{\pi^{0.5} r_{f}}\right)\right]\right\}(1-\beta)\left(1-1.004 \beta+0.418 \beta^{3}+0.210 \beta^{4}-0.1696 \beta^{5}\right)
$$

Here, $\beta=2 a / \mathrm{W}, a$ is the solute radius and $\mathrm{W}$ is the gap spacing of ECS.

Under control conditions, $\mathrm{W}$ is equivalent to $\sim 40 \mathrm{~nm}$ as estimated in the rat brain $\mathrm{ECS}^{37}$. Previously, $\mathrm{Li}$ et al. ${ }^{69}$ used $\mathrm{r}_{\mathrm{f}}=6 \mathrm{~nm}$ and $\mathrm{S}_{\mathrm{f}}=0.326$ to simulate the glycocalyx at the endothelial surface and the ECM in the basement membrane of the BBB in their transport model, which successfully predicted the measured permeability data. Since the BBB endothelial surface glycocalyx and ECM in the BM contain proteoglycans and glycosaminoglycans ${ }^{70}$, similar to those in the brain ECM of the ECS, we assumed the same mean radius of the fiber $r_{f}=6 \mathrm{~nm}$ in the brain ECM, but smaller volume fraction $S_{f}=0.17$. The predicted $D_{\text {eff }} / D_{\text {free }}$ of various sized solutes in the brain tissue by Eq. (2) reconcile with that measured under control conditions. If we assumed that 5-10 min post tDCS transiently enhances the ECS gap spacing W from 40 to $60 \mathrm{~nm}$ (1.5-fold increase) and reduces $\mathrm{S}_{\mathrm{f}}$ from 0.17 to 0.11 (1.54-fold decrease) accordingly, the predicted $\mathrm{D}_{\text {eff }} / \mathrm{D}_{\text {free }}$ also match the measured data. Table 4 summarizes these predictions under control and in response to tDCS. Our predictions suggest a structural mechanism by which tDCS modulates the solute transport in brain tissue.

Because the ECM carries negative charge, it should induce different resistance to the transport of neutral and charged molecules. However, our measured $\mathrm{D}_{\text {eff }} / \mathrm{D}_{\text {free }}$ for the similar sized neutral (Dex-70k) and negatively charged BSA (-19) were not significantly different either under control or in response to tDCS, although the BBB permeability to BSA is significantly smaller than that to Dex-70k under control since endothelial surface glycocalyx and ECM in the basement membrane of the BBB carry negative charges ${ }^{48}$. One possible explanation for this is that the charge density in the ECM of ECS is smaller than that in the endothelial surface glycocalyx and basement membrane of the BBB due to a smaller fiber matrix density $S_{\mathrm{f}}$. The resistance from the steric hindrance and friction is much greater than that from the electrostatic exclusion for these sized molecules.

Transport of solutes are by two mechanisms: diffusion and convection. Diffusion is determined by the solute diffusivity, which is dependent on the solute size, shape, charge, the porosity of the tissue, e.g., available volume in the ECS (interstitial space), and the viscosity of the solution in the interstitial space, temperature, etc. and the driving force, which is the concentration gradient. Convection is the solute transport carried by the fluid flow, which is dependent on the fluid (e.g. CSF) flow velocity and the solute concentration. The driving force for the fluid transport is the pressure gradient. In Xie et al. ${ }^{71}$ and others, they used fluorescent tracers (solutes) to indicate the transport of CSF, which only represents the convection transport of the solutes. However, if the resistance of brain tissue decreases (e.g., ECS increases) to the fluid transport (e.g. CSF transport increases), it should also decrease to the diffusion transport of a solute (solute diffusivity increases) under the same driving forces (e.g. concentration and pressure gradients). Our findings that tDCS enhances solute diffusivity in the brain tissue by modulating the ECS are consistent with theirs. According to Xie et al. ${ }^{71}$, adrenergic signaling not only plays an important role in modulating neuronal activity but also the volume of the interstitial space (ECS). Monai et al. ${ }^{20}$ also reported that tDCS-induced elevation in astrocytic $\mathrm{Ca}^{2+}$ is dependent on alpha- 1 adrenergic receptor. Based on their studies, it is suggested that tDCS modulates the solute brain transport and ECS, as well as the BBB permeability, possibly through an adrenergic signaling pathway.

In conclusion, we report here that in addition to increasing the BBB permeability, tDCS transiently increases the solute transport in the brain tissue, suggesting a new motion of action of $\mathrm{tDCS}$ targeting the ECS by increasing its gap spacing. These findings imply that $\mathrm{tDCS}$ can change the microenvironment surrounding neurons, glial cells and vasculature to achieve its therapeutic effects - though such links remain to be established. Given the universal role of ECS in brain function, this motion of action complementary to standard neurophysiological outcomes of tDCS including altered excitability ${ }^{49,72,73}$ and synaptic plasticity ${ }^{14,19,74,75}$, as well as reported morphological and molecular changes ${ }^{76,77}$. Finally, these findings also suggest that tDCS can be applied to enhance the drug brain delivery, especially macromolecules, through the non-invasive route from the BBB and the minimuminvasive route by CSF if injected through brain ventricles and spinal cord.

\section{Methods}

Animal preparation. All experiments were performed on adult female Sprague-Dawley rats (250-300 g, 3-4 months), supplied by Hilltop Laboratory Animals (Scottdale, PA). The Institutional Animal Care and Use Committee (IACUC) at the City College of the City University of New York approved the animal care and preparation procedures. All experiments were performed in accordance with relevant guidelines and regulations (The protocol number is 964). Rats were anesthetized with sodium pentobarbital injected subcutaneously. The initial dose was $65 \mathrm{mg} / \mathrm{kg}$ bodyweight. The depth of anesthesia was monitored for the absence of withdrawal reflex to toe pinch and absence of blink reflex. Anesthesia was further checked every 15 min during the experiment and 
A
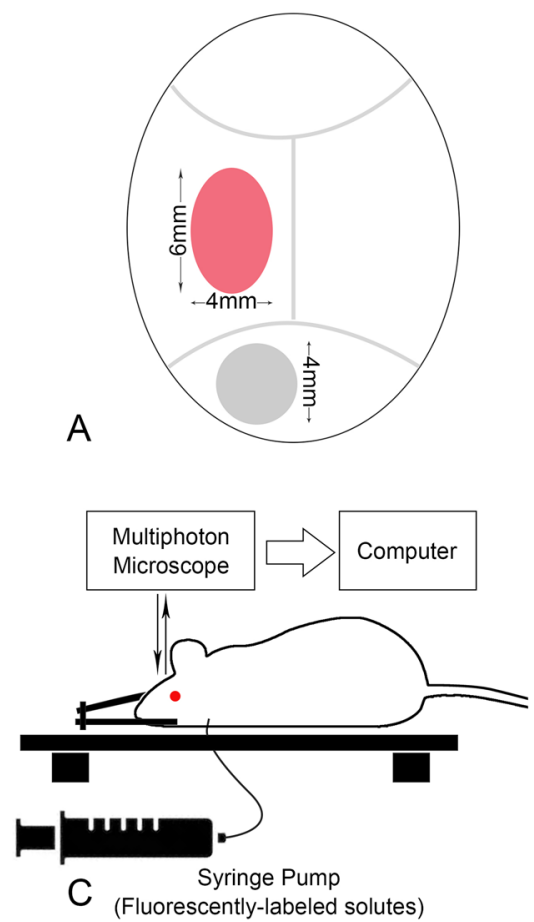

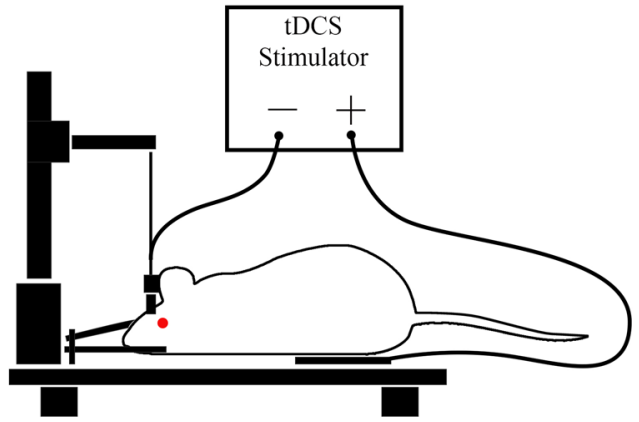

B

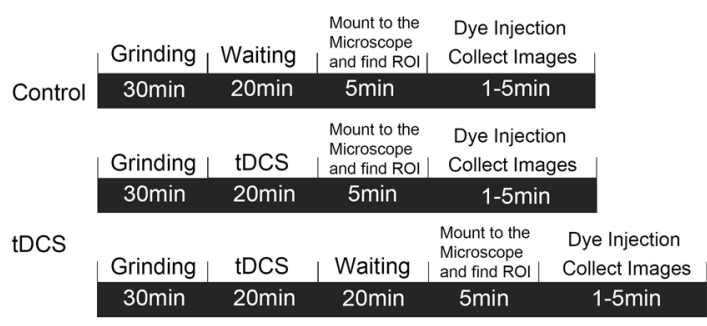

$\mathrm{D}$

Figure 3. Experimental set-ups, timelines and protocols. (A) Illustration showing the locations for the tDCS treatment and imaging on the rat skull. The grey circled region $(\sim 4 \mathrm{~mm}$ diameter $)$ is for the tDCS application. The red elliptical area $(\sim 6 \mathrm{~mm} \times 4 \mathrm{~mm})$ indicates the imaging region with the thinned skull. (B) Sketch for the tDCS application to the rat head. One electrode (-) connects to the rat skull and another electrode $(+)$ connects to the thoracic area. (C) Set-ups for determining the BBB solute permeability $(\mathrm{P})$ and brain tissue diffusion coefficient $\left(\mathrm{D}_{\text {eff }}\right)$ by multiphoton microscopy. Through the imaging region shown by the red ellipse in $(A)$, the ROI containing the microvessel and surrounding tissue is focused in the brain parenchyma $\sim 100-200 \mu \mathrm{m}$ below the pia mater. The images for the ROI are collected simultaneously when the solution with the test solutes is injected via the carotid artery. $\mathrm{P}$ and $\mathrm{D}_{\text {eff }}$ are determined by analyzing the collected images (see Fig. 4) off-line. (D) Sketch for the protocols and timelines for animal skull preparation and image collections for the $\mathrm{P}$ and $\mathrm{D}_{\text {eff }}$ measurement under control and after tDCS.

the rat was given an additional dose of $3 \mathrm{mg} /$ dose as needed. A heating pad was used to keep rat's body temperature in the experiment. When the experiment was done, the animal was euthanized by intravenous injection of an overdose of pentobarbital $(>100 \mathrm{mg} / \mathrm{kg}$ ). The preparation of the rat skull observation area was the same as described in previous studies ${ }^{44,78,79}$. In short, after anesthetized, the region of interest (ROI) on the rat skull was exposed by removing the hair, skin and connective tissue. A $\sim \mathrm{mm}$ by $\sim 4 \mathrm{~mm}$ section (ROI) on the right or left frontoparietal bone (Fig. 3A) was ground with a high-speed micro-grinder (0-50,000 rpm, DLT 50KBU, Brasseler USA, Savannah, GA) until a part of it $(\sim 2 \mathrm{~mm} \times 2 \mathrm{~mm})$ became translucent. In the process, the artificial cerebrospinal fluid (ACSF) at the room temperature was applied to the surface of the skull to remove the heat generated by grinding. After grinding, the carotid artery on the same side of the ROI was cannulated with a PE50 tubing (BD Medical, NJ). The rat was then placed on a stereotaxic alignment system (SAS 597, David Kopf Instruments, Tujunga, CA), and its head was fixed with two ear bars and a mouth clamp. After tDCS treatment, the cross-sectional images of a cerebral microvessel and its surrounding brain tissue were observed and collected by a multiphoton microscope through the translucent part of the skull. The BBB solute permeability and solute diffusion coefficient in the brain tissue were determined off-line from the collected images. Only one experimental condition and 1-2 vessels can be collected in each rat.

Solutions and fluorescent test solutes. Mammalian Ringer's solution. Mammalian Ringer's solution was used for all perfusates, which is composed of (in $\mathrm{mM}$ ) NaCl 132, $\mathrm{KCl} 4.6, \mathrm{MgSO}_{4} 1.2, \mathrm{CaCl}_{2} 2.0, \mathrm{NaHCO}_{3}$ 5.0, glucose 5.5, and HEPES 20. The $\mathrm{pH}$ was buffered to 7.40-7.45 by adjusting the ratio of HEPES acid to base. In addition, the florescent dye solution contained $10 \mathrm{mg} / \mathrm{mL}$ BSA (A4378; Sigma-Aldrich, USA) ${ }^{23,44,79}$. The solutions were made fresh on the day of use to avoid binding to the serum albumin.

Artificial cerebrospinal fluid (ACSF). The ACSF solution composition is (in $\mathrm{mM}$ ) $\mathrm{NaCl} 110.5, \mathrm{KCl} 4.7, \mathrm{CaCl}_{2}$ 2.5, $\mathrm{KH}_{2} \mathrm{PO}_{4} 1.1, \mathrm{MgSO}_{4} \cdot 7 \mathrm{H}_{2} \mathrm{O} 1.25, \mathrm{NaHCO}_{3} 25$, and HEPES. The solution was buffered to $\mathrm{pH} 7.4 \pm 0.5^{23,44,79}$. All chemicals were purchased from Sigma-Aldrich (USA). 
Sodium fluorescein, FITC-BSA and FITC-dextran-70k. Sodium fluorescein (F6377, Sigma-Aldrich; mol. wt. $376 \mathrm{Da}$, Stokes radius $\sim 0.45 \mathrm{~nm}$ ) was dissolved at $0.1 \mathrm{mg} / \mathrm{mL}$ in the Ringer solution containing $10 \mathrm{mg} / \mathrm{mL}$ BSA. FITC-BSA (A9771, Sigma-Aldrich; mol. wt. $\sim 69,000 \mathrm{Da}$, Stokes radius $\sim 3.5 \mathrm{~nm}$ ) and FITC-dextran-70kD (FD70s, Sigma-Aldrich; mol. wt. 70,000 Da, Stokes radius $\sim 3.6 \mathrm{~nm}$ ) was at the concentration of $1 \mathrm{mg} / \mathrm{mL}$ in the Ringer solution containing $10 \mathrm{mg} / \mathrm{mL} \mathrm{BSA}^{44}$. The concentration of the solution for each solute was chosen to be in the linear range of the concentration vs. fluorescence intensity calibrated in Shi et al. ${ }^{44}$.

Transcranial direct current stimulation (tDCS). A constant current stimulator $(1 \times 1 \mathrm{tDCS}$, Soterix Medical Inc, New York, USA) was used to deliver a $1 \mathrm{~mA}$ current for $20 \mathrm{~min}$ for the tDCS as previously described $^{32,80,81}$. To obtain similar physiological outcomes as in the human tDCS application studies ${ }^{32}$, the current was applied transcranially to the frontal cortex of a rat head (approximately $2 \mathrm{~mm}$ anterior to Bregma and $2 \mathrm{~mm}$ right to Sagittal suture) (Fig. 3A). Specifically, an epicranial anode electrode (1 mm diameter, $\mathrm{Ag} / \mathrm{AgCl}$ ) inside a 3D-printed electrode holder (contact area $=12.56 \mathrm{~mm}^{2}$ ) was positioned onto the skull (a round area with $\sim 4 \mathrm{~mm}$ diameter shown in Fig. 3A). A conductive hydrogel uniformly filled the electrode holder (Signa, NJ, USA). A rotating adjustable clamp and a precise micromanipulator from Narishige International USA, Inc. (NY, USA) was used to secure the electrode and the holder in place over the stimulation area. The returning electrode $(5 \times 5 \mathrm{~cm}$ adhesive conductive fabric electrode) from AxelGaard Manufacturing Co., Ltd. (CA, USA) was placed onto the ventral thoracic region of the rat with hair removed (Fig. 3B) and a thin layer of Signa gel was spread to maintain uniform skin-electrode contact. Because the experimental preparation separates the brain region imaged from that directly under the stimulating electrode ${ }^{23,81}$, responses measured here are from brain regions with reduced current density.

Experimental protocol. After tDCS, the rat head was immediately positioned under the multiphoton microscope (Fig. 3C) for the measurement of BBB solute permeability (P) and solute diffusion coefficients in the brain tissue $\left(\mathrm{D}_{\text {eff }}\right)$. Figure $3 \mathrm{D}$ summarizes the experimental protocols for the control and tDCS. It took about 5 min to mount the rat head to the multiphoton microscope and find the ROI. Therefore, the images for the measurement were first collected $\sim 5$ min post-tDCS. Our recent study showed that the BBB permeability transiently increased by tDCS until 20-25 min post $20 \mathrm{~min}-1 \mathrm{~mA}$ tDCS ${ }^{23}$. We thus collected the images $\sim 5$ and 25 min post-tDCS and determined the $\mathrm{D}_{\text {eff }}$ from analyzing these collected images.

Multiphoton microscopy and image collection. An Ultima Multiphoton Microscopy system (Prairie Tech., Inc., WI, USA) was used to collect 12-bit images in vivo. The excitation wavelength was set to $820 \mathrm{~nm}$ for the solutes used in the current study and a water immersion lens $(40 \times /$ NA0.8) was used to observe the microvessels about 100-200 microns below the pia mater ${ }^{44}$. A syringe pump injected the solution with fluorescently labeled solutes at a constant rate of $\sim 3 \mathrm{ml} / \mathrm{min}$ into the cerebral circulation. $3 \mathrm{ml} / \mathrm{min}$ is the normal blood flow rate at the rat carotid artery ${ }^{79}$. The dye took about $10-15 \mathrm{~s}$ from the cannulation site at carotid artery to the cerebral microvessels. While the dye was introduced into the cerebral circulation from the carotid artery, the images were taken simultaneously. The post-capillary venules of $20-40 \mu \mathrm{m}$ diameter ${ }^{23,44,79}$ were selected in a ROI with a volume of $\sim 200 \mu \mathrm{m} \times 8 \mu \mathrm{m} \times 100 \mu \mathrm{m}(\mathrm{x}, \mathrm{y}, \mathrm{z})$ and the images were collected at a rate of 5-15 s/image. The spatial resolution of an image is $\sim 0.47 \mu \mathrm{m} \times 0.47 \mu \mathrm{m} \times 1 \mu \mathrm{m}$ in $\mathrm{x}, \mathrm{y}$ and $\mathrm{z}$ directions. The collected images were then transferred to an image acquisition and analysis workstation for off-line determination of $\mathrm{P}$ and $\mathrm{D}_{\text {eff. }}$.

Image analysis. The Image J (National Institutes of Health) was used to analyze the collected images. First the images were reconstructed into a segment of $200 \mu \mathrm{m} \times 100 \mu \mathrm{m}$ cross-sectional area (x-z) with $8 \mu \mathrm{m}$ thickness. The temporal and spatial solute intensity (concentration) profiles $I(t, x, z)$ surrounding a microvessel in this volume of the brain tissue were determined by the ImageJ program.

Determination of the BBB solute permeability $P$ and effective solute diffusion coefficient $D_{\text {eff }}$ in brain tissue. The same method as in our previous study was used to determine the permeability $(P)$ of the cerebral microvessels and effective solute diffusion coefficient $\left(D_{\text {eff }}\right)$ in brain tissue ${ }^{23,44}$. A cross-sectional image $(\mathrm{x}-\mathrm{z})$ of a rat cerebral microvessel filled with a solution of fluorescently-labeled solutes and the surrounding brain tissue was illustrated in Fig. 4A. The white dashed line circled region is the ROI to determine P. The caption for Fig. 4B describes how to determine the BBB solute permeability P. Figure 4C,D illustrate how to determine $\mathrm{D}_{\text {eff }}$ from the collected images. $D_{\text {eff }}$ was determined by fitting the temporal and spatial intensity curves by an unsteady mathematical model for solute transport in the tissue space ${ }^{82}$

$$
\frac{\partial C_{t}}{\partial t}=\mathrm{D}_{\mathrm{eff}}\left(\frac{\partial^{2} C_{t}}{\partial r^{2}}+\frac{1}{r} \frac{\partial C_{t}}{\partial r}\right)-\chi u \frac{\partial C_{t}}{\partial r}
$$

where $C_{t}(t, r)$ is the concentration of solutes in the tissue space, $D_{\text {eff }}$ is the effective diffusion coefficient of solutes in tissue, $r$ is the distance from the vessel center. $\chi$ is the retardation coefficient of a solute in the tissue, estimated as $0.1-1$ for solutes under study ${ }^{47}$. $u$ is the interstitial fluid velocity in brain tissue. The Peclet number $\mathrm{P}_{\mathrm{et}}$ in the tissue is ${ }^{83}$,

$$
P_{e t}=\frac{\chi V L_{t}}{\mathrm{D}_{\mathrm{eff}}}
$$



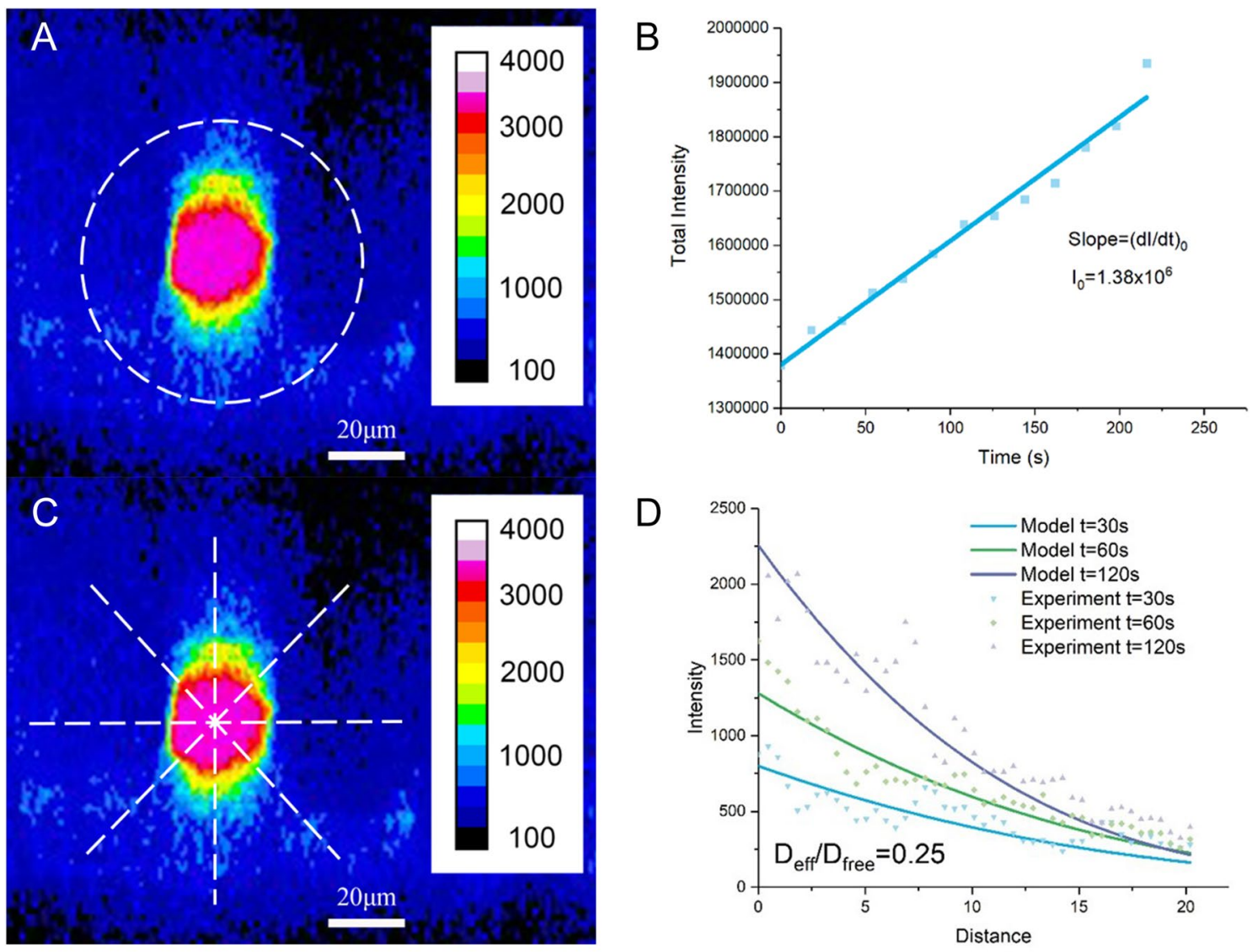

Figure 4. Methods for determining BBB solute permeability $(\mathrm{P})$ and solute diffusion coefficient in rat brain tissue $\left(D_{\text {eff }}\right)$. (A) A cross-sectional image showing a cerebral microvessel filled with fluorescent solutes and the surrounding tissue. The dashed line enclosed region is the ROI for determining P. The edge of the dashed line is about $10-30 \mu \mathrm{m}$ far from the vessel wall to prevent contamination from the neighboring microvessels. The ROI should be enough large to include the spreading dye from the lumen of the vessel during image collection for the P measurement. (B) Curve for total intensity of the test solutes in the ROI vs. perfusion time. The slope of the curve $(\mathrm{dI} / \mathrm{dt})_{0}$ during the initial solute accumulation period is used for determining $\mathrm{P} . \mathrm{P}=1 / \mathrm{I}_{0}{ }^{\star}(\mathrm{dI} / \mathrm{dt})_{0}{ }^{\star} \mathrm{r} / 2$. $\mathrm{I}_{0}$ is total fluorescence intensity in the vessel lumen and $\mathrm{r}$ is the vessel radius. (C) From the cross-sectional image of the ROI, radial lines in 8 directions are drawn from the vessel center. (D) The intensity averaged from the eight radial lines is plotted from the vessel wall at different times $(t=30,60$ and $120 \mathrm{~s})$ (dotted lines). The solid smooth lines are the best fitting curves of the model prediction at the corresponding times when the correct effective solute diffusion coefficient $\mathrm{D}_{\text {eff }}$ is chosen. $\mathrm{D}_{\text {eff }} / \mathrm{D}_{\text {free }}=0.25\left(\mathrm{D}_{\text {free }}\right.$ is the free solute diffusion coefficient in an aqueous solution at $37^{\circ} \mathrm{C}$ ) is the best fitting value for this run of the experiment for FITC-BSA 5-10 min post tDCS.

Here $\mathrm{L}_{\mathrm{t}}$ is the characteristic length for the solute tissue transport, which is the mean half distance $(\sim 20 \mu \mathrm{m})$ between adjacent microvessels ${ }^{84}, V$ is the characteristic interstitial fluid velocity, which is approximated by the outflow velocity from the vessel wall $\mathrm{L}_{\mathrm{p}} \Delta \mathrm{p}_{\mathrm{eff}} \cdot \mathrm{L}_{\mathrm{p}}$ is the hydraulic conductivity of the microvessel, $\sim 2 \times 10^{-9} \mathrm{~cm} / \mathrm{s} /$ $\mathrm{cm} \mathrm{H} \mathrm{O}_{2} \mathrm{O}^{85}$, while $\Delta \mathrm{p}_{\text {eff }}$ is the effective pressure difference across the vessel wall, which is less than $10 \mathrm{~cm}_{2} \mathrm{O}^{79}$. For the size range of solutes in this study, $\mathrm{D}_{\text {eff }}$ is in the range of $10^{-6} \sim 10^{-8} \mathrm{~cm}^{2} / \mathrm{s}, \mathrm{P}_{\mathrm{et}}$ was calculated as in the order of $10^{-5}-10^{-2}$ even assuming that the $\mathrm{L}_{\mathrm{p}}$ increases by 100 folds due to tDCS treatment. Due to the very low Peclet number, the convection part can be neglected in Eq. (3). Equation (3) becomes,

$$
\frac{\partial \mathrm{C}_{\mathrm{t}}}{\partial \mathrm{t}}=\mathrm{D}_{\mathrm{eff}}\left(\frac{\partial^{2} \mathrm{C}_{\mathrm{t}}}{\partial \mathrm{r}^{2}}+\frac{1}{\mathrm{r}} \frac{\partial \mathrm{C}_{\mathrm{t}}}{\partial \mathrm{r}}\right)
$$

The boundary conditions for Eq. (5) are,

$$
\begin{aligned}
& \text { at the vessel wall } r=a, P\left(C_{\text {lumen }}-C_{t}\right)=D_{\text {eff }} \frac{\partial C_{t}}{\partial r} \\
& \text { midway between adjacent vessels } r=b, \quad \frac{\partial C_{t}}{\partial r}=0
\end{aligned}
$$


where $\mathrm{C}_{\text {lumen }}$ is the solute concentration in the vessel lumen, $\mathrm{P}$ is the microvessel solute permeability. Both of which can be determined from the collected images. The only unknown parameter in Eqs. (5)-(8) is $\mathrm{D}_{\text {eff. }}$ Solving above Eq. (5) with an assumed value of $\mathrm{D}_{\text {eff }}$ by Matlab, we obtained the theoretical solute tissue concentration profiles $\mathrm{C}_{t}\left(t, r_{t}\right)$. To obtain the measured $C_{t}\left(t, r_{t}\right)$, eight straight lines were drawn from the center of a vessel lumen to a distance $\sim 20 \mu \mathrm{m}$ from the vessel wall in the tissue space (Fig. $4 \mathrm{C}$ ), the averaged intensity from these 8 directions was approximated as the measured $\mathrm{C}_{\mathrm{t}}\left(\mathrm{t}, \mathrm{r}_{\mathrm{t}}\right)$, which was plotted in Fig. 4D (colored dots, distance $r_{t}=0$ is at the vessel wall). The $\mathrm{D}_{\text {eff }}$ was determined by the best curve-fitting of the model predictions (colored lines in Fig. 4D) to the measured profiles.

Influence of red blood cells (RBCs), free dye, and solvent drag on BBB permeability. While the dye solution was injected at the perfusion rate of $3 \mathrm{ml} / \mathrm{min}$, the normal blood flow rate at the rat carotid artery $^{86,87}$, there was still residue blood (red blood cells, RBCs) in the cerebral microvessels. As estimated in Yuan et $\mathrm{al}^{79}$, this residue blood overestimates the measured BBB permeability $\mathrm{P}^{\text {measure }}$ by $\sim 11 \%$, Besides RBCs, free dye overestimates the permeability to the solutes labeled with the fluorescent dye ${ }^{79,88}$. The solute permeability affected by the free dye was estimated by $\mathrm{P}^{\text {correct }}=[1 /(1-\mathrm{F})] \mathrm{P}^{\text {measure }}-[\mathrm{F} /(1-\mathrm{F})] \mathrm{P}^{\text {freedye88}}$, where $\mathrm{P}^{\text {correct }}$ is the corrected permeability; $\mathrm{P}^{\text {freedye }}$ is the permeability to the free dye. Because the size of sodium fluorescein $(\mathrm{NaFl}, 376)$ is similar to that of FITC (389.4), $\mathrm{P}^{\text {freedye }} \sim \mathrm{P}^{\mathrm{NaFl}}$; F is the intensity ratio of the free dye filtrate to the fluorescently labeled solution. $\mathrm{F}$ is $\sim 0.1 \%$ for the FITC-labeled solutes in the current study; The above corrected P still overestimates the true diffusive solute permeability $\mathrm{P}_{\mathrm{d}}$ due to the solvent drag coupled to the fluid flow. The following equations were used to find the $\mathrm{P}_{\mathrm{d}}$ of the solutes under this study ${ }^{88,89}$,

$$
\begin{gathered}
P=P_{d} \frac{P e}{\exp (P e-1)}+L_{p}(1-\sigma) \Delta p_{e f f} \\
P_{e}=\frac{L_{p}(1-\sigma) \Delta p_{e f f}}{P_{d}}
\end{gathered}
$$

where $\mathrm{L}_{\mathrm{p}}$, the hydraulic conductivity of the microvessel, is $\sim 2.0 \times 10^{-9} \mathrm{~cm} / \mathrm{s} / \mathrm{cm} \mathrm{H}_{2} \mathrm{O}$ for the cerebral microvessels ${ }^{44,85}, P_{e}$ is the Peclet number. The reflection coefficient of the microvessel to the solute is $\sigma$ and the effective filtration pressure $\Delta p_{\text {eff }}$ across the microvessel wall is calculated from

$$
\Delta p_{\text {eff }}=\Delta p-\sigma^{\text {albumin }} \Delta \pi^{\text {albumin }}-\sigma^{\text {dye-solute }} \Delta \pi^{\text {dye-solute }}
$$

Here the hydrostatic pressure difference across the cerebral microvessel wall $\Delta p$ was $\sim 10 \mathrm{~cm} \mathrm{H}_{2} \mathrm{O}$, and the osmotic pressure difference $\Delta \pi^{\text {albumin }}$ was $3.6 \mathrm{~cm} \mathrm{H}_{2} \mathrm{O}$ for $1 \% \mathrm{BSA}^{79}$. The superscript dye-solute is FITC-BSA, Dex-70k or sodium fluorescein. Based on the previous studies ${ }^{79}, \sigma$ of rat cerebral microvessels to the test solutes were estimated as 0.95 and 0.1 , respectively, for $\sigma^{\text {dextran-70k }}$ (the same as $\sigma^{\text {albumin }}$ ) and $\sigma^{\text {NaFl }}$. In correcting influence from the solvent drag in the permeability, for the control group and 25-30 min post tDCS group, $\mathrm{L}_{\mathrm{p}, \text { control }}=2 \times 10^{-9} \mathrm{~cm} / \mathrm{s} / \mathrm{cm} \mathrm{H}_{2} \mathrm{O}$; for the 5-10 min post tDCS group, $100 \times \mathrm{L}_{\mathrm{p} \text {,control }}$ was used.

Data analysis and statistics. Data are presented as means \pm SE. The control $P$ was the average value of the permeability measured under control. This control $\mathrm{P}$ value was used to normalize all the subsequent treatments correspondingly. $D_{\text {eff }}$ was given as $D_{\text {eff }} / D_{\text {free }}$. Here, $D_{\text {free }}$ is the free solute diffusion coefficient in water at $37^{\circ} \mathrm{C}$. The statistical significance was determined by applying ANOVA to the treatment at different times and to between-group data for the differences at specific times. $p<0.05$ was considered statistically significant.

Received: 26 May 2020; Accepted: 13 October 2020

Published online: 28 October 2020

\section{References}

1. Truong, D. Q. \& Bikson, M. Physics of transcranial direct current stimulation devices and their history. J. ECT 34, 137-143. https ://doi.org/10.1097/yct.0000000000000531 (2018).

2. Antal, A. et al. Low intensity transcranial electric stimulation: safety, ethical, legal regulatory and application guidelines. Clin. Neurophysiol. 128, 1774-1809. https://doi.org/10.1016/j.clinph.2017.06.001 (2017).

3. Woods, A. J. et al. A technical guide to tDCS, and related non-invasive brain stimulation tools. Clin. Neurophysiol. 127, 1031-1048. https://doi.org/10.1016/j.clinph.2015.11.012 (2016).

4. Nitsche, M. A. \& Paulus, W. Excitability changes induced in the human motor cortex by weak transcranial direct current stimulation. J. Physiol. 527(Pt 3), 633-639 (2000).

5. Ekhtiari, H. et al. Transcranial electrical and magnetic stimulation (tES and TMS) for addiction medicine: a consensus paper on the present state of the science and the road ahead. Neurosci. Biobehav. Rev. 104, 118-140. https://doi.org/10.1016/j.neubi orev.2019.06.007 (2019).

6. Fregni, F. et al. Regulatory considerations for the clinical and research use of transcranial direct current stimulation (tDCS): review and recommendations from an expert panel. Clin. Res. Regul. Aff. 32, 22-35. https://doi.org/10.3109/10601333.2015.980944 (2015).

7. Brunoni, A. R. et al. Clinical research with transcranial direct current stimulation (tDCS): challenges and future directions. Brain Stimul. 5, 175-195. https://doi.org/10.1016/j.brs.2011.03.002 (2012).

8. Vicario, C. M., Salehinejad, M. A., Felmingham, K., Martino, G. \& Nitsche, M. A. A systematic review on the therapeutic effectiveness of non-invasive brain stimulation for the treatment of anxiety disorders. Neurosci. Biobehav. Rev. 96, 219-231. https://doi. org/10.1016/j.neubiorev.2018.12.012 (2019). 
9. Jackson, M. P. et al. Animal models of transcranial direct current stimulation: methods and mechanisms. Clin. Neurophysiol. 127, 3425-3454. https://doi.org/10.1016/j.clinph.2016.08.016 (2016).

10. Kenney-Jung, D. L., Blacker, C. J., Camsari, D. D., Lee, J. C. \& Lewis, C. P. Transcranial direct current stimulation: mechanisms and psychiatric applications. Child. Adolesc. Psychiatr. Clin. N. Am. 28, 53-60. https://doi.org/10.1016/j.chc.2018.07.008 (2019).

11. Giordano, J. et al. Mechanisms and effects of transcranial direct current stimulation. Dose Response 15, 1559325816685467. https ://doi.org/10.1177/1559325816685467 (2017)

12. Bikson, M., Name, A. \& Rahman, A. Origins of specificity during tDCS: anatomical, activity-selective, and input-bias mechanisms. Front. Hum. Neurosci. 7, 688. https://doi.org/10.3389/fnhum.2013.00688 (2013).

13. Sathappan, A. V., Luber, B. M. \& Lisanby, S. H. The dynamic duo: combining noninvasive brain stimulation with cognitive interventions. Prog. Neuropsychopharmacol. Biol. Psychiatr. 89, 347-360. https://doi.org/10.1016/j.pnpbp.2018.10.006 (2019).

14. Kronberg, G., Rahman, A., Sharma, M., Bikson, M. \& Parra, L. C. Direct current stimulation boosts hebbian plasticity in vitro. Brain Stimul. 13, 287-301. https://doi.org/10.1016/j.brs.2019.10.014 (2020).

15. Brocker, D. T. \& Grill, W. M. Principles of electrical stimulation of neural tissue. Handb. Clin. Neurol. 116, 3-18. https://doi. org/10.1016/b978-0-444-53497-2.00001-2 (2013).

16. Lopez-Quintero, S. V. et al. DBS-relevant electric fields increase hydraulic conductivity of in vitro endothelial monolayers. J. Neural Eng. 7, 16005. https://doi.org/10.1088/1741-2560/7/1/016005 (2010).

17. Pelletier, S. J. \& Cicchetti, F. Cellular and molecular mechanisms of action of transcranial direct current stimulation: evidence from in vitro and in vivo models. Int. J. Neuropsychopharmacol. https://doi.org/10.1093/ijnp/pyu047 (2014).

18. Rahman, A. et al. Cellular effects of acute direct current stimulation: somatic and synaptic terminal effects. J. Physiol. 591, 25632578. https://doi.org/10.1113/jphysiol.2012.247171 (2013).

19. Kronberg, G., Bridi, M., Abel, T., Bikson, M. \& Parra, L. C. Direct current stimulation modulates LTP and LTD: activity dependence and dendritic effects. Brain Stimul. 10, 51-58. https://doi.org/10.1016/j.brs.2016.10.001 (2017).

20. Monai, H. et al. Calcium imaging reveals glial involvement in transcranial direct current stimulation-induced plasticity in mouse brain. Nat. Commun. 7, 11100. https://doi.org/10.1038/ncomms11100 (2016).

21. Monai, H. \& Hirase, H. Astrocytes as a target of transcranial direct current stimulation (tDCS) to treat depression. Neurosci. Res. 126, 15-21. https://doi.org/10.1016/j.neures.2017.08.012 (2018).

22. Cancel, L. M., Arias, K., Bikson, M. \& Tarbell, J. M. Direct current stimulation of endothelial monolayers induces a transient and reversible increase in transport due to the electroosmotic effect. Sci. Rep. 8, 9265 (2018).

23. Shin, D. W. et al. In vivo modulation of the blood-brain barrier permeability by transcranial direct current stimulation (tDCS). Ann. Biomed. Eng. https://doi.org/10.1007/s10439-020-02447-7 (2020).

24. Farkas, E. \& Luiten, P. G. Cerebral microvascular pathology in aging and Alzheimer's disease. Prog. Neurobiol. 64, 575-611 (2001).

25. Abbott, N. J., Rönnbäck, L. \& Hansson, E. Astrocyte-endothelial interactions at the blood-brain barrier. Nat. Rev. Neurosci. 7, 41 (2006).

26. Fu, B. M. Transport across the blood-brain barrier. Adv. Exp. Med. Biol. 1097, 235-259. https://doi.org/10.1007/978-3-319-96445 $-4 \_13(2018)$.

27. Stagg, C. J. et al. Widespread modulation of cerebral perfusion induced during and after transcranial direct current stimulation applied to the left dorsolateral prefrontal cortex. J. Neurosci. Off. J. Soc. Neurosci. 33, 11425-11431. https://doi.org/10.1523/JNEUR OSCI.3887-12.2013 (2013)

28. Giorli, E. et al. Transcranial direct current stimulation and cerebral vasomotor reserve: a study in healthy subjects. J. Neuroimaging Off. J. Am. Soc. Neuroimaging 25, 571-574. https://doi.org/10.1111/jon.12162 (2015).

29. Wang, Y. et al. Direct current stimulation over the human sensorimotor cortex modulates the brain's hemodynamic response to tactile stimulation. Eur. J. Neurosci. 42, 1933-1940. https://doi.org/10.1111/ejn.12953 (2015).

30. Mielke, D. et al. Cathodal transcranial direct current stimulation induces regional, long-lasting reductions of cortical blood flow in rats. Neurol. Res. 35, 1029-1037. https://doi.org/10.1179/1743132813Y.0000000248 (2013).

31. Barbati, S. A. et al. Enhancing plasticity mechanisms in the mouse motor cortex by anodal transcranial direct-current stimulation: the contribution of nitric oxide signaling. Cereb. Cortex 30, 2972-2985. https://doi.org/10.1093/cercor/bhz288 (2020).

32. Marceglia, S. et al. Transcranial direct current stimulation modulates cortical neuronal activity in Alzheimer's disease. Front. Neurosci. 10, 134. https://doi.org/10.3389/fnins.2016.00134 (2016).

33. Nicholson, C. \& Syková, E. Extracellular space structure revealed by diffusion analysis. Trends Neurosci. 21, 207-215 (1998).

34. Syková, E. \& Nicholson, C. Diffusion in brain extracellular space. Physiol. Rev. 88, 1277-1340 (2008).

35. Tonnesen, J., Inavalli, V. \& Nagerl, U. V. Super-resolution imaging of the extracellular space in living brain tissue. Cell 172, 11081121.e1115. https://doi.org/10.1016/j.cell.2018.02.007 (2018).

36. Wolak, D. J. \& Thorne, R. G. Diffusion of macromolecules in the brain: implications for drug delivery. Mol. Pharm. 10, 1492-1504 (2013).

37. Nicholson, C. \& Hrabětová, S. Brain extracellular space: the final frontier of neuroscience. Biophys. J. 113, 2133-2142 (2017).

38. Ruoslahti, E. Brain extracellular matrix. Glycobiology 6, 489-492 (1996).

39. Barros, C. S., Franco, S. J. \& Müller, U. Extracellular matrix: functions in the nervous system. Cold Spring Harbor Perspect. Biol. 3, a005108 (2011).

40. Thorne, R. G., Lakkaraju, A., Rodriguez-Boulan, E. \& Nicholson, C. In vivo diffusion of lactoferrin in brain extracellular space is regulated by interactions with heparan sulfate. Proc. Natl. Acad. Sci. 105, 8416-8421 (2008).

41. Dityatev, A., Seidenbecher, C. I. \& Schachner, M. Compartmentalization from the outside: the extracellular matrix and functional microdomains in the brain. Trends Neurosci. 33, 503-512 (2010).

42. Dityatev, A. \& Schachner, M. Extracellular matrix molecules and synaptic plasticity. Nat. Rev. Neurosci. 4, 456-468. https://doi. org/10.1038/nrn1115 (2003).

43. Kamali-Zare, P. \& Nicholson, C. Brain extracellular space: geometry, matrix and physiological importance. Basic Clin. Neurosci. 4, 282-286 (2013).

44. Shi, L., Zeng, M., Sun, Y. \& Fu, B. M. Quantification of blood-brain barrier solute permeability and brain transport by multiphoton microscopy. J. Biomech. Eng. 136, 031005 (2014).

45. Thorne, R. G. \& Nicholson, C. In vivo diffusion analysis with quantum dots and dextrans predicts the width of brain extracellular space. Proc. Natl. Acad. Sci. 103, 5567-5572 (2006).

46. Lv, Y., Cheung, N.-K.V. \& Fu, B. M. A pharmacokinetic model for radioimmunotherapy delivered through cerebrospinal fluid for the treatment of leptomeningeal metastases. J. Nucl. Med. 50, 1324-1331 (2009).

47. Chen, B. \& Fu, B. M. A time-dependent electrodiffusion-convection model for charged macromolecule transport across the microvessel wall and in the interstitial space. Cell. Mol. Bioeng. 2, 514 (2009).

48. Li, G. \& Fu, B. M. An electrodiffusion model for the blood-brain barrier permeability to charged molecules. J. Biomech. Eng. 133, $021002(2011)$

49. Bikson, M. et al. Effects of uniform extracellular DC electric fields on excitability in rat hippocampal slices in vitro. J. Physiol. 557, 175-190. https://doi.org/10.1113/jphysiol.2003.055772 (2004).

50. Radman, T., Ramos, R. L., Brumberg, J. C. \& Bikson, M. Role of cortical cell type and morphology in subthreshold and suprathreshold uniform electric field stimulation in vitro. Brain Stimul. 2(215-228), 228.e211-213. https://doi.org/10.1016/j.brs.2009.03.007 (2009). 
51. Chakraborty, D., Truong, D. Q., Bikson, M. \& Kaphzan, H. Neuromodulation of axon terminals. Cereb. Cortex 28, 2786-2794. https://doi.org/10.1093/cercor/bhx158 (2018).

52. Baczyk, M. \& Jankowska, E. Presynaptic actions of transcranial and local direct current stimulation in the red nucleus. J. Physiol. 592, 4313-4328. https://doi.org/10.1113/jphysiol.2014.276691 (2014).

53. Baudewig, J., Nitsche, M. A., Paulus, W. \& Frahm, J. Regional modulation of BOLD MRI responses to human sensorimotor activation by transcranial direct current stimulation. Magn. Reson. Med. 45, 196-201. https://doi.org/10.1002/1522-2594(20010 2)45:2\%3c196::aid-mrm1026\%3e3.0.co;2-1 (2001).

54. Lang, N. et al. How does transcranial DC stimulation of the primary motor cortex alter regional neuronal activity in the human brain?. Eur. J. Neurosci. 22, 495-504. https://doi.org/10.1111/j.1460-9568.2005.04233.x (2005).

55. Nicholson, C. \& Phillips, J. Ion diffusion modified by tortuosity and volume fraction in the extracellular microenvironment of the rat cerebellum. J. Physiol. 321, 225-257 (1981).

56. Lehmenkühler, A., Syková, E., Svoboda, J., Zilles, K. \& Nicholson, C. Extracellular space parameters in the rat neocortex and subcortical white matter during postnatal development determined by diffusion analysis. Neuroscience 55, 339-351 (1993).

57. Sykova, E. et al. Changes in extracellular space size and geometry in APP23 transgenic mice: a model of Alzheimer's disease. Proc. Natl. Acad. Sci. U. S. A. 102, 479-484. https://doi.org/10.1073/pnas.0408235102 (2005).

58. Sykova, E. et al. Learning deficits in aged rats related to decrease in extracellular volume and loss of diffusion anisotropy in hippocampus. Hippocampus 12, 269-279. https://doi.org/10.1002/hipo.1101 (2002).

59. Voříšek, I. \& Syková, E. Ischemia-induced changes in the extracellular space diffusion parameters, $\mathrm{K}+$, and pH in the developing rat cortex and corpus callosum. J. Cereb. Blood Flow Metab. 17, 191-203 (1997).

60. Simonova, Z. et al. Changes of extracellular space volume and tortuosity in the spinal cord of Lewis rats with experimental autoimmune encephalomyelitis. Physiol. Res. 45, 11-22 (1996).

61. Slais, K. et al. Brain metabolism and diffusion in the rat cerebral cortex during pilocarpine-induced status epilepticus. Exp. Neurol. 209, 145-154. https://doi.org/10.1016/j.expneurol.2007.09.008 (2008).

62. Bikson, M. et al. Safety of transcranial direct current stimulation: evidence based update 2016. Brain Stimul. 9, 641-661. https:// doi.org/10.1016/j.brs.2016.06.004 (2016).

63. Zewdie, E. et al. Safety and tolerability of transcranial magnetic and direct current stimulation in children: prospective single center evidence from 3.5 million stimulations. Brain Stimul. 13, 565-575. https://doi.org/10.1016/j.brs.2019.12.025 (2020).

64. Bikson, M. et al. Limited output transcranial electrical stimulation (LOTES-2017): engineering principles, regulatory statutes, and industry standards for wellness, over-the-counter, or prescription devices with low risk. Brain Stimul. 11, 134-157. https://doi. org/10.1016/j.brs.2017.10.012 (2018).

65. Paneri, B. et al. Tolerability of repeated application of transcranial electrical stimulation with limited outputs to healthy subjects. Brain Stimul. 9, 740-754. https://doi.org/10.1016/j.brs.2016.05.008 (2016).

66. Abbott, N. J. Evidence for bulk flow of brain interstitial fluid: significance for physiology and pathology. Neurochem. Int. 45, 545-552 (2004).

67. Fu, B. M. Experimental methods and transport models for drug delivery across the blood-brain barrier. Curr. Pharm. Biotechnol. 13, 1346-1359 (2012).

68. Sugihara-Seki, M. \& Fu, B. M. M. Blood flow and permeability in microvessels. Fluid Dyn. Res. 37, 82-132. https://doi.org/10.1016/j. fluiddyn.2004.03.006 (2005).

69. Li, G., Yuan, W. \& Fu, B. M. A model for the blood-brain barrier permeability to water and small solutes. J. Biomech. 43, 2133-2140 (2010).

70. Fu, B. M. \& Tarbell, J. M. Mechano-sensing and transduction by endothelial surface glycocalyx: composition, structure, and function. Wiley Interdiscip. Rev. Syst. Biol. Med. 5, 381-390 (2013).

71. Xie, L. et al. Sleep drives metabolite clearance from the adult brain. Science (New York, N.Y.) 342, 373-377. https://doi.org/10.1126/ science.1241224 (2013).

72. Lafon, B., Rahman, A., Bikson, M. \& Parra, L. C. Direct current stimulation alters neuronal input/output function. Brain Stimul. 10, 36-45. https://doi.org/10.1016/j.brs.2016.08.014 (2017).

73. Nitsche, M. A. et al. Pharmacological modulation of cortical excitability shifts induced by transcranial direct current stimulation in humans. J. Physiol. 553, 293-301. https://doi.org/10.1113/jphysiol.2003.049916 (2003).

74. Fritsch, B. et al. Direct current stimulation promotes BDNF-dependent synaptic plasticity: potential implications for motor learning. Neuron 66, 198-204. https://doi.org/10.1016/j.neuron.2010.03.035 (2010).

75. Kim, M. S. et al. Repeated anodal transcranial direct current stimulation induces neural plasticity-associated gene expression in the rat cortex and hippocampus. Restor. Neurol. Neurosci. 35, 137-146. https://doi.org/10.3233/rnn-160689 (2017).

76. Keuters, M. H. et al. Transcranial direct current stimulation promotes the mobility of engrafted NSCs in the rat brain. NMR Biomed. 28, 231-239. https://doi.org/10.1002/nbm.3244 (2015).

77. Pelletier, S. J. et al. The morphological and molecular changes of brain cells exposed to direct current electric field stimulation. Int. J. Neuropsychopharmacol. https://doi.org/10.1093/ijnp/pyu090 (2014).

78. Shin, D. W., Khadka, N., Fan, J., Bikson, M. \& Fu, B. M. in Medical Imaging 2016: Biomedical Applications in Molecular, Structural, and Functional Imaging. 97881X (International Society for Optics and Photonics).

79. Yuan, W., Lv, Y., Zeng, M. \& Fu, B. M. Non-invasive measurement of solute permeability in cerebral microvessels of the rat. Microvasc. Res. 77, 166-173. https://doi.org/10.1016/j.mvr.2008.08.004 (2009).

80. Liebetanz, D. et al. Safety limits of cathodal transcranial direct current stimulation in rats. Clin. Neurophysiol. 120, 1161-1167. https://doi.org/10.1016/j.clinph.2009.01.022 (2009).

81. Jackson, M. P. et al. Safety parameter considerations of anodal transcranial direct current stimulation in rats. Brain Behav. Immun. 64, 152-161. https://doi.org/10.1016/j.bbi.2017.04.008 (2017).

82. Fu, B. M., Adamson, R. H. \& Curry, F.-R. E. Determination of microvessel permeability and tissue diffusion coefficient of solutes by laser scanning confocal microscopy. (2005).

83. Fu, B., Curry, F.-R.E., Adamson, R. H. \& Weinbaum, S. A model for interpreting the tracer labeling of interendothelial clefts. Ann. Biomed. Eng. 25, 375-397 (1997).

84. Duvernoy, H., Delon, S. \& Vannson, J. The vascularization of the human cerebellar cortex. Brain Res. Bull. 11, 419-480 (1983).

85. Kimura, M., Dietrich, H. H., Huxley, V. H., Reichner, D. R. \& Dacey, R. G. Jr. Measurement of hydraulic conductivity in isolated arterioles of rat brain cortex. Am. J. Physiol. 264, H1788-H1797. https://doi.org/10.1152/ajpheart.1993.264.6.H1788 (1993).

86. Brown, R. C., Egleton, R. D. \& Davis, T. P. Mannitol opening of the blood-brain barrier: regional variation in the permeability of sucrose, but not 86Rb+ or albumin. Brain Res. 1014, 221-227. https://doi.org/10.1016/j.brainres.2004.04.034S0006899304006432 [pii] (2004).

87. Garcia-Villalon, A. L., Roda, J. M., Alvarez, F., Gomez, B. \& Dieguez, G. Carotid blood flow in anesthetized rats: effects of carotid ligation and anastomosis. Microsurgery. 13, 258-261 (1992).

88. Fu, B. M., Adamson, R. H. \& Curry, F. E. Test of a two-pathway model for small-solute exchange across the capillary wall. Am. J. Physiol. 274, H2062-H2073 (1998).

89. Fu, B. M. \& Shen, S. Structural mechanisms of acute VEGF effect on microvessel permeability. Am. J. Physiol. 284, H2124-H2135 (2003). 


\section{Acknowledgements}

This work was supported by the U.S. National Institutes of Health Grants R01NS101362 (BMF and MB), 1R01NS095123 (MB), 1R01NS112996 (MB) and 1UG3TR002151-01 (BMF and KWL).

\section{Author contributions}

The experiments described here were performed in the Microcirculation Laboratory at the City College of the City University of New York. B.M.F. and Y.X. contributed to the conception and design of the work. Y.X., W.K., Z.Y., G.H. and B.M.F. contributed to acquisition, analysis, or interpretation of data for the work. Y.X., M.B. and BMF contributed to drafting and revising the work. All authors approved the final version of the manuscript. All authors agree to be accountable for all aspects of the work in ensuring that questions related to the accuracy or integrity of any part of the work are appropriately investigated and resolved. All persons designated as authors qualify for authorship, and all those who qualify for authorship are listed.

\section{Competing interests}

The City University of New York holds patents on brain stimulation with MB as inventor. MB has equity in Soterix Medical Inc. MB consults and/or serves on the SAB of Boston Scientific, GlaxoSmithKline, Mecta, Halo Neuroscience. YX, WK, ZY, GH and BMF declare no potential conflict of interest.

\section{Additional information}

Correspondence and requests for materials should be addressed to B.M.F.

Reprints and permissions information is available at www.nature.com/reprints.

Publisher's note Springer Nature remains neutral with regard to jurisdictional claims in published maps and institutional affiliations.

(c) (i) Open Access This article is licensed under a Creative Commons Attribution 4.0 International License, which permits use, sharing, adaptation, distribution and reproduction in any medium or format, as long as you give appropriate credit to the original author(s) and the source, provide a link to the Creative Commons licence, and indicate if changes were made. The images or other third party material in this article are included in the article's Creative Commons licence, unless indicated otherwise in a credit line to the material. If material is not included in the article's Creative Commons licence and your intended use is not permitted by statutory regulation or exceeds the permitted use, you will need to obtain permission directly from the copyright holder. To view a copy of this licence, visit http://creativecommons.org/licenses/by/4.0/.

(C) The Author(s) 2020 